\title{
An improved crystal structure of C-phycoerythrin from the marine cyanobacterium Phormidium sp. A09DM
}

\author{
Ravi R. Sonani ${ }^{1} \cdot$ Aleksander W. Roszak $^{2}$ • \\ Claire Ortmann de Percin Northumberland ${ }^{2} \cdot$ Datta Madamwar $^{1}$. \\ Richard J. Cogdell ${ }^{2}$
}

Received: 1 March 2017 / Accepted: 8 September 2017 / Published online: 16 September 2017

(C) The Author(s) 2017. This article is an open access publication

\begin{abstract}
C-Phycoerythrin (PE) from Phormidium sp. A09DM has been crystallized using different conditions and its structure determined to atomic resolution $(1.14 \AA)$. In order for the pigment present, phycoerythrobilin (PEB), to function as an efficient light-harvesting molecule it must be held rigidly (Kupka and Scheer in Biochim Biophys Acta 1777:94-103, 2008) and, moreover, the different PEB molecules in PE must be arranged, relative to each other, so as to promote efficient energy transfer between them. This improved structure has allowed us to define in great detail the structure of the PEBs and their binding sites. These precise structural details will facilitate theoretical calculations of each PEB's spectroscopic properties. It was possible, however, to suggest a model for which chromophores contribute to the different regions of absorption spectrum and propose a tentative scheme for energy transfer. We show that some subtle differences in one of these PEB binding sites in two of the 12 subunits are caused by crystal contacts between neighboring hexamers in the crystal lattice.
\end{abstract}

Ravi R. Sonani and Aleksander W. Roszak have shared first authorship and contributed equally to this work.

Electronic supplementary material The online version of this article (doi:10.1007/s11120-017-0443-2) contains supplementary material, which is available to authorized users.

Aleksander W. Roszak

aleksander.roszak@glasgow.ac.uk

$\triangle$ Datta Madamwar

datta_madamwar@yahoo.com

1 Post-Graduate Department of Biosciences, UGC-Centre of Advanced Study, Sardar Patel University, Vadtal Road, Satellite Campus, Bakrol, Anand, Gujarat 388315, India

2 Institute of Molecular Cell an Systems Biology, University of Glasgow, 120 University Place, Glasgow G12 8TA, UK
This explains some of the differences seen in previous lower resolution structures determined at two different $\mathrm{pH}$ values (Kumar et al. in Photosyn Res 129:17-28, 2016).

Keywords Photosynthesis - Cyanobacteria .

Phycobilisomes · Phycoerythrin · PEB chromophores ·

Atomic resolution crystal structure

$\begin{array}{ll}\text { Abbreviations } \\ \text { MPD } & \text { (4S)-2-methyl-2,4-pentanediol } \\ \text { APC } & \text { Allophycocyanin } \\ \text { PE } & \text { C-phycoerythrin } \\ \text { DLS } & \text { Diamond Light Source } \\ \text { MeN } & \text { Methylated Asn, } \gamma \text { - } N \text {-methylasparagine } \\ \text { NPS } & \text { Nitrate Phosphate Sulphate } \\ \text { OD } & \text { Optical density } \\ \text { PC } & \text { Phycocyanin } \\ \text { PEB } & \text { Phycoerythrobilin } \\ \text { PEG-1K } & \text { Polyethylene glycol } 1000\end{array}$

\section{Introduction}

The major light-harvesting complexes of cyanobacteria and red algae are the phycobilisomes (Zhao et al. 2012). These large, water-soluble pigment-protein complexes bind to the surface of the photosynthetic membranes and funnel absorbed light energy into the chlorophyll-containing photosystems. The phycobilisomes are usually made up of phycoerythrin (PE), phycocyanin (PC) and allophycocyanin (APC). They are arranged so that PE (absorption maximum $\left.A_{\max } 540-570 \mathrm{~nm}\right)$ is on the outside of the structure, PC $\left(\mathrm{A}_{\max } 610-620 \mathrm{~nm}\right)$ is in the middle and APC $\left(\mathrm{A}_{\max } 655 \mathrm{~nm}\right)$ is nearest to the photosynthetic membrane. This then sets up an energy gradient that 'directs' energy transfer downhill to 
the photosystems. PE and PC typically form rods that join onto the central APC discs. Mainly colorless linker proteins play a key role in organizing the overall structure of the phycobilisome and subtly modulate the absorption properties of the phycobiliproteins to which they bind.

PEs are oligomers of a basic heterodimer that consists of $\alpha$ - and $\beta$-subunits (conventionally referred as $\alpha \beta$ monomer) to which bile pigments are covalently attached through conserved cysteine residues. These monomer units then oligomerise to form trimers $\left[(\alpha \beta)_{3}\right]$ and then stacked hexamers $\left\{\left[(\alpha \beta)_{3}\right]_{2}\right\}$. The structure of this complex was first determined at two different $\mathrm{pH}$ values of 5 and 8.5 to the resolutions of 1.93 and $2.12 \AA$, respectively (PDB IDs: $5 \mathrm{fvb}$ and 5aqd, respectively; Kumar et al. 2016). Since then we have been able to significantly improve the quality of the crystals of this pigment-protein complex and have determined its structure to atomic resolution of $1.14 \AA$. The best possible structures for light-harvesting complexes are important since this information can then be used for theoretical studies designed to understand the detailed spectroscopic properties of the pigments involved in the light-harvesting processes. For example, see the quantum mechanics/molecular mechanics calculations performed for the cryptophyte PE545 antenna (Aghtar et al. 2017; Curutchet and Mennucci 2017 and other references within) based on the $0.97 \AA$ resolution structure of PE545 from unicellular cryptophyte Rhodomonas CS24 (Doust et al. 2004). In the case of PE from Phormidium sp. A09DM the pigment present is phycoerythrobilin (PEB) bound covalently to PE protein via one or two $\mathrm{C}_{\mathrm{PEB}}-\mathrm{S}_{\mathrm{Cys}}$ bonds; its structure is shown in Fig. 1. One of the major ways in which the apoprotein controls where an individual PEB absorbs (its site energy) is by 'distorting' the planarity of the bilin. This then changes the effective conjugation length (Gaigalas et al. 2006). Reducing the conjugation length will cause a blue shift of the PEB's absorption spectrum. This effect was described previously (Doust et al. 2004; Curutchet et al. 2013) for the PEB pigments from cryptophyte PE545. On top of this the site energies of the individual PEB molecules will be further influenced by more subtle aspects of the pigments' local environment (Doust et al. 2004; Curutchet et al. 2011; Aghtar et al. 2017). The present report will describe the overall PEB binding pockets in more detail than was previously discussed for the cyanobacterial PE from Phormidium sp. A09DM (Kumar et al. 2016). This earlier study also described subtle differences in the two crystal structures related to crystals being grown at different $\mathrm{pHs}, \mathrm{pH} 5$ and $\mathrm{pH} 8.5$, respectively. Our atomic resolution structure explains these previous findings.

\section{Materials and methods}

\section{Protein purification}

The PE was isolated and purified from marine cyanobacteria Phormidium sp. A09DM as described earlier (Sonani et al. 2015; Kumar et al. 2016).

\section{Analysis of absorption spectrum}

The absorption spectrum of PE in $20 \mathrm{mM}$ Tris-buffer $(\mathrm{pH}$ 8.0) was recorded at $25^{\circ} \mathrm{C}$ in a UV-visible spectrophotometer (Specord 210, Analytik Jena AG, Jena, Germany). This spectrum was then deconvoluted into Gaussian decomposition components using the Gaussian algorithm present in the OriginPro8 software (OriginLab, Northampton, MA).

\section{Circular dichroism (CD) spectrum}

CD spectrum of $\mathrm{PE}$ in the region of 400-600 $\mathrm{nm}$ was recorded at room temperature in $0.2 \mathrm{~cm}$ cuvette using a $\mathrm{J}-810$ spectrophotometer (JASCO). The PE sample was dissolved in $20 \mathrm{mM}$ Tris-buffer ( $\mathrm{pH}$ 8.0) and had an absorption of 1 at the maximum of the absorption spectrum.

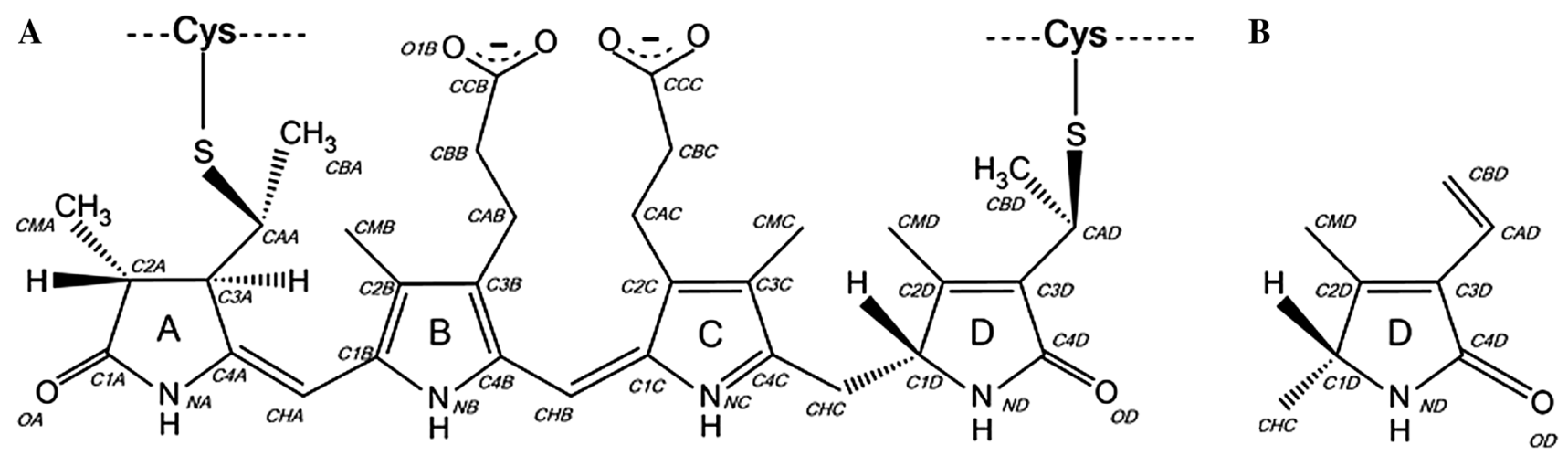

Fig. 1 a Chemical structure of phycoerythrobilin PEB188, which is attached to PE protein via two thioether bonds; b chemical structure of D-ring of the PEB chromophore attached to protein by a single thioether bond; rings A, B and C are identical as in PEB in diagram (a) 


\section{Crystallization of PE}

Crystallization trials of purified PE were set up using the following range of sparse matrix screens, JCSG-plus, PACT premier, Morpheus, MIDAS and Structure, which were all obtained from Molecular Dimensions. The screening was carried out by a crystallization robot Cartesian Honeybee $8+1$ (Genomic Solutions Ltd) using sitting drop vapour diffusion in 96-well 2-drop MRC crystallization plates (Molecular Dimensions). These trials (with PE at an OD 75 at $564 \mathrm{~nm})$ yielded reasonable size crystals $(100 \times 80 \times 80$ microns) within 6 days in conditions C8 [37.5\% v/v Precipitant Mixture MPD_P1K_P3350; Buffer System 2 [Na HEPES; MOPS (acid)] pH 7.5; $0.09 \mathrm{M}$ mix of additive nitrate phosphate sulphate (NPS)] and G8 [37.5\% v/v Precipitant Mixture MPD_P1K_P3350; Buffer System 2, $\mathrm{pH} 7.5 ; 0.1 \mathrm{M}$ mix of carboxylic acids] of the Morpheus screen. Both conditions at $\mathrm{pH} 7.5, \mathrm{C} 8$ and G8, were further optimized using a larger volume 24-well plates (Cryschem, NBS Biologicals) and the purified PE in a buffer consisting of $20 \mathrm{mM}$ Tris- $\mathrm{HCl} \mathrm{pH} 8.0$, concentrated to $10 \mathrm{mg} / \mathrm{mL}$. Diffraction-quality crystals of $300 \times 200 \times 100$ micron were obtained in 15 days in both conditions. The details of the optimized conditions are shown in Table S1 in the Supplementary Material.

\section{Data collection and analysis}

The optimized PE crystals were scooped up from the crystallization droplets in the LithoLoops (Molecular Dimensions) and flash-cooled in nitrogen gas at $100 \mathrm{~K}$. Both Morpheus crystallization conditions, C8 and G8, contain sufficient amounts of cryoprotectants like MPD and PEG$1 \mathrm{~K}$ so no extra cryoprotection was needed. These crystals diffracted to about 1.5-1.7 ̊ resolution during tests using our in-house X-ray setup (Rigaku MicroMax-007 generator and mar345dtb detector). The best crystals were sent to the Diamond Light Source (DLS) synchrotron near Oxford, UK, where diffraction data were collected at $100 \mathrm{~K}$ on beamlines I04 and I04-1 using detector Pilatus 6M-F (Dectris AG). Table 1 presents the data collection, processing and refinement statistics for the highest-resolution datasets obtained for both pH 7.5 crystals, from Morpheus C8 and G8 conditions. The data were indexed, integrated, scaled and evaluated using the following programs; XDS (Kabsch 2010), POINTLEES (Evans 2006), AIMLESS (Evans and Murshudov 2013), autoPROC (Vonrhein et al. 2011), xia2 (Winter 2010) and the other programs from the CCP4 suite (Winn et al. 2011).

The symmetry of data and of the $\mathrm{pH} 7.5$ crystals was found to be $P 1$ as was the symmetry of the $\mathrm{pH} 5$ and 8.5 crystals obtained before (Kumar et al. 2016). Similarly, the unit cell dimensions of all crystals are almost identical with no bigger difference than $1.7 \%$. The asymmetric unit of these crystals, the whole unit cell, is comprised of $12 \alpha \beta$ monomers organized in two stacked hexamers $\left\{\left[(\alpha \beta)_{3}\right]_{2}\right\}$. The 12 $\alpha$-subunits are labelled A to $\mathrm{L}$, while the $12 \beta$-subunits are labelled M to X. There are two PEB molecules, PEB166 $\alpha$ and PEB $167 \alpha$, attached to each $\alpha$-subunit and three, PEB $186 \beta$, PEB187 $\beta$ and PEB188 $\beta$, to each $\beta$-subunit.

Due to high internal similarity of the new crystals to the earlier ones the phasing of diffraction data was directly obtained by the process of rigid-body refinement in REFMAC5 (Murshudov et al. 2011) of the $2.12 \AA \mathrm{pH} 8.5$ structure of PE from Phormidium sp. A09DM (PDB ID: 5aqd; Kumar et al. 2016) against the new $1.14 \AA$ data. The $R_{\text {free }}$ reflections were also copied from the 5aqd structure and extended to $1.14 \AA$ resolution, then copied again to $1.38 \AA$ data. Model refined against $1.14 \AA$ data was then used and remodelled when necessary in refinement against the $1.38 \AA$ data. All structure modelling was performed in COOT (Emsley et al. 2010). Due to the available amount of the experimental data the refinements of both $\mathrm{pH} 7.5 \mathrm{PE}$ structures presented here were finished with the introduction of anisotropic atomic B factors. Program RAMPAGE (Lovell et al. 2003) was used to evaluate stereochemistry of the structures and only the single residue in $\beta$-subunit, Pro73, was found slightly off the allowed region of the Ramachandran plot in both structures, although it was perfectly fitted within the strong electron density. The atomic coordinates and structure factors have been deposited in the Protein Data Bank with the accession ID codes $5 \mathrm{nb} 4$ and 5nb3, for the PE from Morpheus conditions C8 and G8, respectively.

\section{Results and discussion}

\section{Atomic resolution structure of C-phycoerythrin}

PE from Phormidium sp. A09DM has been successfully crystallized from two different Morpheus screen conditions at the $\mathrm{pH}$ of 7.5. Details of the general composition of this PE protein and its crystal structure have been reported earlier (Kumar et al. 2016). The description of the atomic resolution structure of PE will be presented here using the model based on the $1.14 \AA$ data for the crystal grown in NPS conditions (Morpheus C8) while the model based on the $1.38 \AA$ data (crystal grown in carboxylic acids mix, Morpheus G8) will only be mentioned explicitly in the cases of significant structural differences.

Experimental data extending to $1.14 \AA$ A resolution allow for a very high precision of structure to be determined. The coordinate error estimated in the maximum likelihood refinement of this structure is $0.03 \AA$, which is almost an order of magnitude smaller than the equivalent value $(0.25 \AA$ ) estimated for the earlier $1.93 \AA \mathrm{pH} 5$ model (PDB 
Table 1 Data collection, processing and refinement statistics for the PE complex from Phormidium sp. A09DM

\begin{tabular}{|c|c|c|}
\hline Morpheus crystallization condition & $\mathrm{C} 8$ & G8 \\
\hline Protein Data Bank accession code & $5 \mathrm{nb} 4$ & $5 \mathrm{nb} 3$ \\
\hline Space group & $P 1$ & $P 1$ \\
\hline Unit cell $a, b, c(\AA)$ & 109.046, 109.095, 117.371 & $110.046,110.170,118.516$ \\
\hline Unit cell $\alpha, \beta, \gamma\left({ }^{\circ}\right)$ & $78.78,82.32,60.26$ & $78.76,82.28,60.43$ \\
\hline Data measured at beamline & I04 at DLS & I04-1 at DLS \\
\hline Detector used & Pilatus 6M-F & Pilatus 6M-F \\
\hline Wavelength $(\AA)$ & 0.97951 & 0.92819 \\
\hline Resolution range (outer shell) ${ }^{\mathrm{a}}(\AA)$ & $94.60-1.14(1.16-1.14)$ & $93.40-1.38(1.42-1.38)$ \\
\hline Unique reflections & $1,575,226(74,960)$ & $932,250(67,249)$ \\
\hline Redundancy & $2.6(2.7)$ & $2.9(2.8)$ \\
\hline Completeness $(\%)$ & $93.8(90.0)$ & $95.7(93.2)$ \\
\hline$R_{\text {merge }}^{\mathrm{b}}(\%)$ & $4.2(54.5)$ & $7.7(80.1)$ \\
\hline Mean $I / \sigma$ & $10.7(1.6)$ & $7.3(1.3)$ \\
\hline Half-set correlation coefficient ${ }^{\mathrm{c}} \mathrm{CC}_{1 / 2}$ & $0.998(0.601)$ & $0.997(0.477)$ \\
\hline Refinement $R_{\text {work }} / R_{\text {free }}$ factors $^{\mathrm{d}}(\%)$ & $14.7 / 18.4$ & $15.5 / 21.1$ \\
\hline Ramachandran plot features ${ }^{\mathrm{e}}(\%)$ & $98.2 / 1.5 / 0.3$ & $98.1 / 1.6 / 0.3$ \\
\hline Rms dev. bond lengths/angles $\left(\AA{ }^{\circ}\right)$ & $0.017 / 2.68$ & $0.018 / 2.60$ \\
\hline 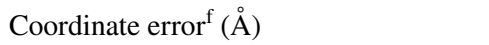 & $0.035 / 0.031$ & $0.066 / 0.059$ \\
\hline No. of non-H atoms used in refinement & 43,607 & 43,181 \\
\hline No. of water molecules & 8168 & 7843 \\
\hline Mean atomic/Wilson plot $B$ factors $\left(\AA^{2}\right)$ & $15.6 / 9.7$ & $15.9 / 8.2$ \\
\hline
\end{tabular}

${ }^{a}$ Values in parentheses are for the highest-resolution outer shell

${ }^{\mathrm{b}} R_{\text {merge }}=\sum_{h k l} \sum_{i}\left|I_{i}(h k l)-<I(h k l)>\right| / \sum_{h k l} \sum_{i} I_{i}(h k l)$

${ }^{c}$ The experimental unmerged data are divided into two parts, each containing a random half of the measurements of each unique reflection. The correlation coefficient $\mathrm{CC}_{1 / 2}$ is then calculated between the average intensities of each subset (Karplus and Diederichs 2012)

${ }^{\mathrm{d}} R_{\text {work }}$ and $R_{\text {free }}=\sum_{h k l}|| F_{o}(h k l)|-| F_{c}(h k l)|| / \sum_{h k l}\left|F_{o}(h k l)\right| ; R_{\text {work }}$ was calculated for all data except for 5\% that was used for the $R_{\text {free }}$ calculations

${ }^{\mathrm{e}}$ Percentages of residues in most favoured/additionally allowed/disallowed regions by RAMPAGE (Lovell et al. 2003)

${ }^{\mathrm{f}}$ Estimated standard uncertainty; first value calculated using the method of Cruickshank (Cruickshank 1999), second one based on maximum likelihood as implemented in REFMAC (Murshudov et al. 2011)
ID: 5 fvb; Kumar et al. 2016). This difference in precision is important for the quality of structure-based theoretical modelling of spectroscopic properties (Mennucci 2017, personal communication). Figure 2 illustrates the quality of electron density maps calculated for the $1.14 \AA$ 跑olution PE structure. A typical refinement of the protein structure model is performed by the use of the combination of experimental X-ray diffraction intensities produced by the protein crystal and the restraints coming from the prior knowledge of protein structure bond distances, bond angles and torsion angles. The higher the resolution is, and therefore the number of the experimental data, the larger is the contribution of the actual X-ray diffraction experiment in such a refinement. At resolutions better than about $1.2 \AA$ (Rupp 2010) discrete atoms are distinctly visible in the electron density maps and these effects are clearly seen in Fig. 2.

\section{Description of protein microenvironments of chromophores}

Deviations from planarity of the five PEB pigment molecules present in each PE $\alpha \beta$ monomer and the likely effects of these on the position of the pigment's absorption maxima were already described earlier (Kumar et al. 2016). These deviations are represented by the angles between the pyrrole rings $\mathrm{A}$ and $\mathrm{B}$, which are part of the conjugated $\mathrm{A}-\mathrm{B}-\mathrm{C}$-ring system of PEB pigment (see Fig. 1). The B- and C-rings are approximately coplanar with each other in all PEB molecules found in the PE structures, while the ring A strongly deviates from this central ' $\mathrm{B}-\mathrm{C}$ ' plane. It has been shown that such deviations from coplanarity of the A- and B-rings correlate with a decrease of the extent of $\pi$-coupling of the PEB-conjugated system and cause a blue shift in the position of the absorption maximum (Gaigalas et al. 2006). The 

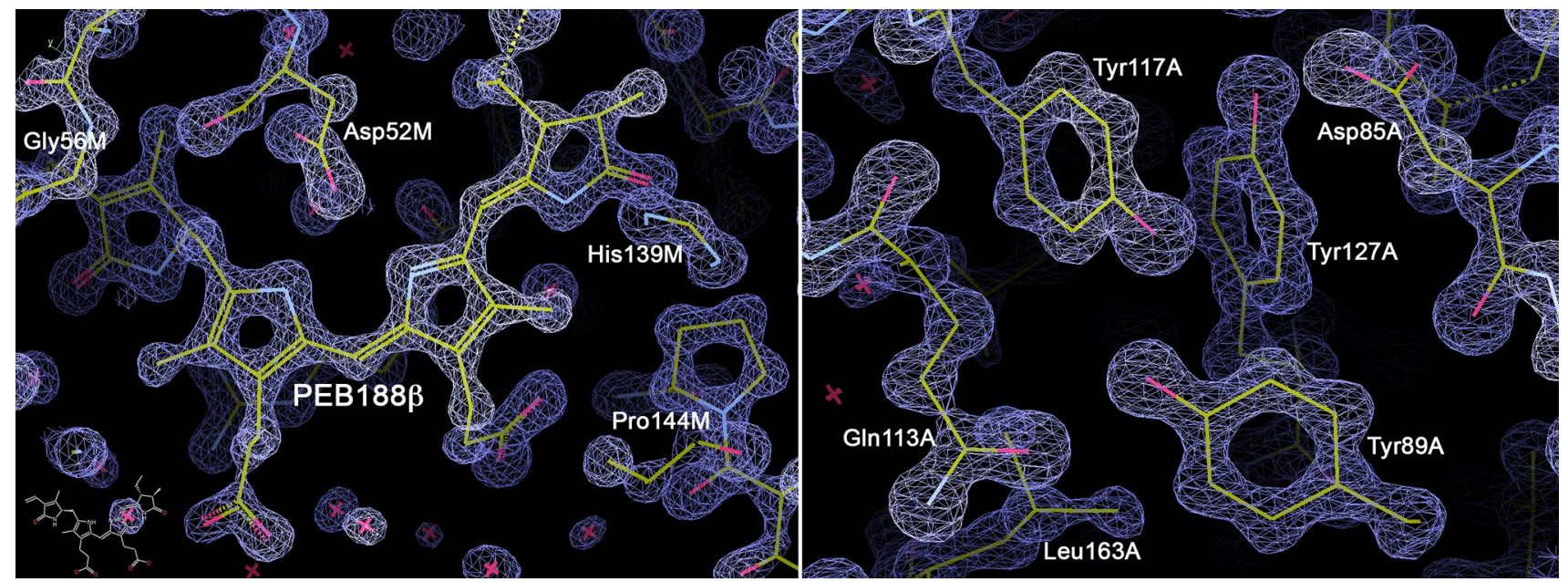

Fig. 2 Representative examples of the 1.14 A electron density map $2 F o-F c$ at contour level 2.5 sigma for the PE from Phormidium sp. A09DM; these images were prepared using program COOT (Emsley et al. 2010)

average values of these deviations for the 12 independent molecules in the $P 1$ cell for the crystal diffracting to $1.14 \AA$ resolution are $25.6(1.0)^{\circ}, 39.4(2.3)^{\circ}, 21.5(0.9)^{\circ}, 32.8(1.2)^{\circ}$ and $42.6(1.0)^{\circ}$ for the chromophores PEB166 $\alpha$, PEB167 $\alpha$, PEB186 $\beta$, PEB187 $\beta$ and PEB188 $\beta$, respectively. Values in brackets are the standard deviations for the 12 molecules in the cell. The exact angles for the individual 60 pigments are shown in Table S2 in the Supplementary Material. The authors of the earlier work (Kumar et al. 2016) concluded that the direction of energy flow could, therefore, be expected to be from the PEB molecules in the outer surface of the hexamer $\left\{\left[(\alpha \beta)_{3}\right]_{2}\right\}$, which show 'high-deviations' from planarity and, consequently, an absorption at shorter wavelengths compared to those of the 'lower-deviation' pigments (absorbing in longer wavelengths) located near to hollow inner cavity. In vivo, this cavity harbours the linker polypeptide (also called $\gamma$-subunit).

In PE from Phormidium sp. A09DM the PEB167 $\alpha$ pigment is the outer-most 'high-deviation' chromophore, which is located on the outside surface of the $\alpha$-subunit. The specific protein microenvironment of the PEB $167 \alpha$ molecule, which is shown in Fig. 3a for the $\alpha$-subunit A (the same arrangement is found for $\alpha$-subunits B...L), compensates for its high exposure to the solvent phase and holds it in a well-defined fixed orientation. First of all the Asp143 and the carbonyl group of Arg137 residue anchor the PEB167 $\alpha$ molecule in place via two $\mathrm{H}$-bonds to a water molecule which itself forms two $\mathrm{H}$-bonds to the $\mathrm{NB}$ and $\mathrm{NC}$ atoms of pyrrole rings $\mathrm{B}$ and $\mathrm{C}$, respectively. Secondly, the side chains of two arginine residues, Arg137 and Arg142, interact via $\pi$-stacking with the central conjugated moiety of the PEB167 $\alpha$, hence contributing to a well-defined orientation of this pigment molecule. These arginine side chains are kept in place by forming two H-bonds each with the PEB B- and
C-ring propionic groups, respectively. Additionally, residue Glu54 also interacts via two H-bonds with the Arg137 side chain, while the Asp143 helps to hold the Arg142 side chain via one more $\mathrm{H}$-bond. Finally, the $\mathrm{C}_{\mathrm{PEB}}-\mathrm{S}_{\mathrm{Cys}}$ covalent bond between A-ring of PEB 167 $\alpha$ and Cys139, plus the H-bonds between the D-ring carbonyl group and residues Asn47 and Lys43 (not shown in Fig. 3a), hold the pigment rings $\mathrm{A}$ and $\mathrm{D}$ in place, respectively, and also fix the deviation of ring A from planarity from the central conjugated portion of PEB 167 $\alpha$. Several more H-bonds between PEB 167 $\alpha$ and the surrounding solvent water molecules are formed, for full details of these interactions and also of all hydrophobic contacts see the LigPlot+ (Laskowski and Swindells 2011) diagram (Fig. S1A) in the Supplementary Material. In particular, one water molecule links the pigment's B-ring propionic group with its A-ring NA atom while another one links the pigment's C-ring propionic group with its D-ring ND atom, so they both also contribute to the control of the overall shape and rigidity of this pigment molecule.

PEB $187 \beta$, the second 'high-deviation' chromophore, is located a bit deeper into the $\beta$-subunit of PE but is still partially exposed to the solvent phase outside of the hexamer. The protein microenvironment of this pigment is shown in Fig. $3 \mathrm{~b}$ for $\beta$-subunit $\mathrm{M}$ (the same arrangement is found for $\beta$-subunits N...X). Residues Cys165 and Asp37 hold the PEB187 $\beta$ molecule in place via the $\mathrm{C}_{\mathrm{PEB}}-\mathrm{S}_{\mathrm{Cys}}$ covalent bond between Cys 165 and PEB ring A, and the two H-bonds between the Asp37 side chain and the pigment's NB and $\mathrm{NC}$ atoms of its rings $\mathrm{B}$ and $\mathrm{C}$, respectively. Additionally, the two H-bonds between Arg34 side chain and PEB B-ring propionic group fix the defined orientation of the PEB187 $\beta$ molecule. The second PEB propionic group, bound to ring $\mathrm{C}$, interacts by $\mathrm{H}$-bonding with four water molecules, one of them $\mathrm{H}$-bonds residue Gln147 from a neighboring $\alpha$-subunit 
Fig. 3 Geometry and interactions of chromophores a PEB $167 \alpha$ in $\alpha$-subunit A (same for B to L), $\mathbf{b}$ PEB187 $\beta$ in $\beta$-subunit $\mathrm{M}$ (same for $\mathrm{N}$ to $\mathrm{X}), \mathbf{c}$ PEB186 $\beta$ in $\beta$-subunit $\mathrm{M}$ (same for $\mathrm{N}$ to $\mathrm{X}$ ), $\mathbf{d}$ PEB $166 \alpha$ in $\alpha$-subunit A (same for B to $\mathrm{L}$ ), and e PEB $188 \beta$ in $\beta$-subunit $\mathrm{M}$ (same for X), and $\mathbf{f}$ PEB $188 \beta$ in $\beta$-subunit $\mathrm{N}$ (same for $\mathrm{O}$ to $\mathrm{W}$ ), within protein matrix. Hydrogen bonds are presented as yellow dashed lines. Water molecules are shown as red spheres. This figure was prepared using PyMOL (Schrodinger, LLC)
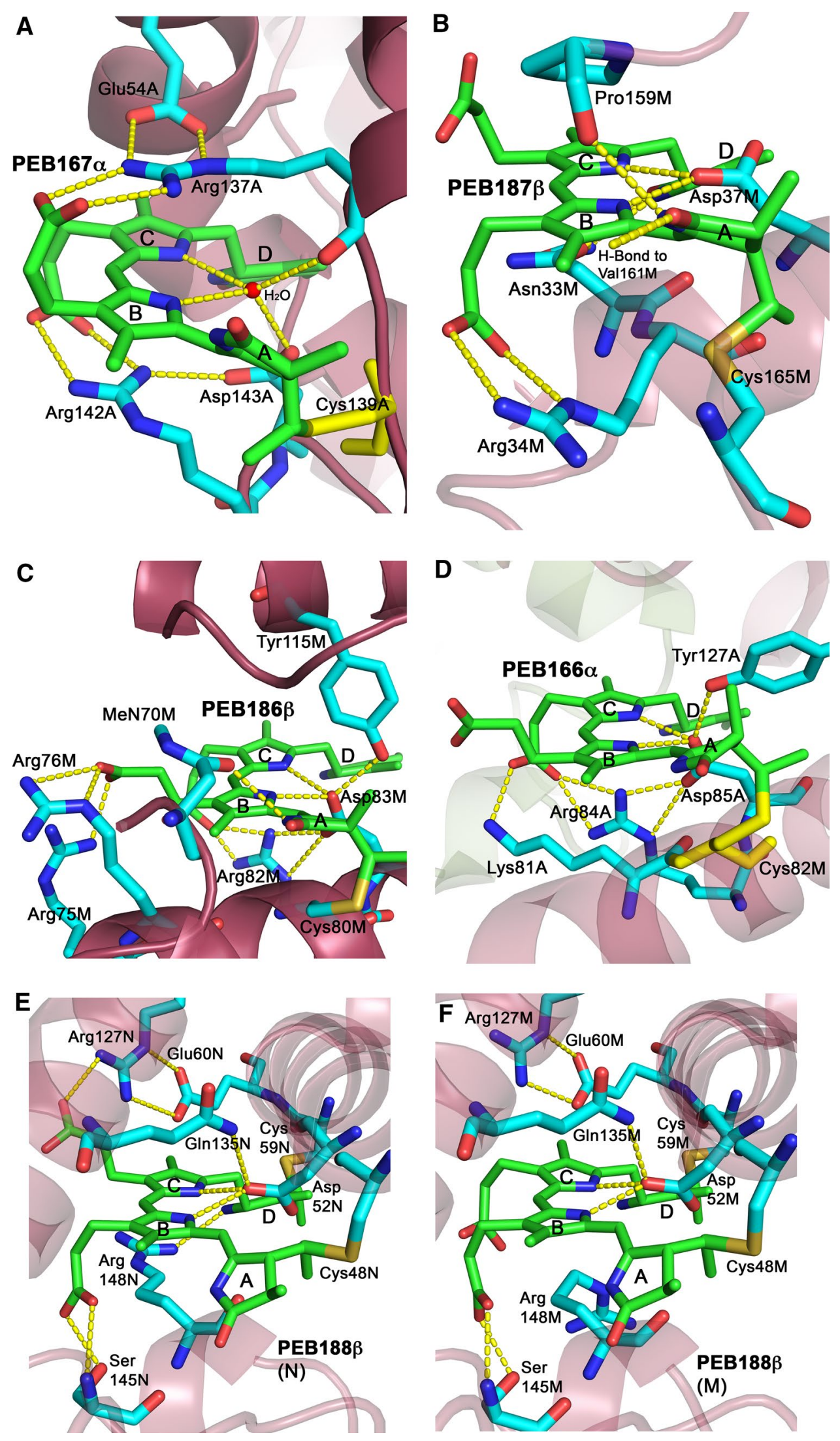
D (not shown in Fig. 3b, see full details in Fig. S1B in the Supplementary Material). Finally, beside the $\mathrm{C}_{\mathrm{PEB}}-\mathrm{S}_{\mathrm{Cys}}$ covalent bond there are also four $\mathrm{H}$-bonds which hold the pigment rings $\mathrm{A}$ and $\mathrm{D}$ in place and fix the deviations of these rings from planarity relative to the central conjugated portion of PEB187 $\beta$. The carbonyl O-atom of Pro159 and the main chain $\mathrm{N}$-atom of Val161 (residue not shown, $\mathrm{H}$-bond shown in Fig. 3b) are H-bonding the NA and carbonyl O-atoms of the pigment's A-ring, respectively, while the side chains of Gln28 (from the $\alpha$-subunit A, not shown in Fig. 3b) and Asn33 are H-bonding the D-ring carbonyl O- and NA atoms, respectively. In the PEB187 $\beta$ molecule there are no internal cross-links between the PEB A- and D-rings, and the propionic groups.

The chromophore PEB $186 \beta$ of $\beta$-subunit is located near the central hexamer cavity and it is one of the two pigments that show the least deviation from planarity (the other being PEB166 $\alpha$ ). The protein microenvironment of this pigment is shown in Fig. $3 c$ for chain $M$ (the same arrangement is found for $\beta$-subunits N...X). Residues Cys80 and Asp83 hold the PEB $186 \beta$ molecule in place via the $\mathrm{C}_{\mathrm{PEB}}-\mathrm{S}_{\mathrm{Cys}}$ covalent bond between Cys 80 and PEB ring $\mathrm{A}$, and the two H-bonds between the Asp83 side chain and the pigment's $\mathrm{NB}$ and $\mathrm{NC}$ atoms of its rings $\mathrm{B}$ and $\mathrm{C}$, respectively. The Asp83 side chain is held in place by the H-bond to Tyr115. The PEB $186 \beta$ molecule orientation is held by the PEB Band $\mathrm{C}$-ring propionic groups interacting via three $\mathrm{H}$-bonds with side chains of residues Arg75 and Arg76 for B-ring and Arg82 for C-ring, respectively. Two propionic groups are also 'linked' by the H-bonds to a single water molecule (not shown in Fig. 3c). Finally, beside the $\mathrm{C}_{\mathrm{PEB}}-\mathrm{S}_{\mathrm{Cys}}$ covalent bond there is also one $\mathrm{H}$-bond, between the ring's NA atom and the side chain of residue MeN70 (methylated Asn, $\gamma-N$ methylasparagine), that holds the pigment ring $\mathrm{A}$ in place and helps to define the deviation of the ring A from planarity from the central conjugated rings B and C of the PEB186 $\beta$. Depending on the $\beta$-subunit either two or three $\mathrm{H}$-bonds are formed between the D-ring and solvent water molecules, of which one always $\mathrm{H}$-bonds $\mathrm{Arg} 82$ side chain, and these are shown together with all hydrophobic interactions in Fig. S1C in the Supplementary Material.

The chromophore PEB166 $\alpha$ is the second pigment that has a low deviation from planarity. It is located about halfway between the inner cavity and the outer-most perimeter of the $\left\{\left[(\alpha \beta)_{3}\right]_{2}\right\}$ hexamer, and near the interface between $\alpha$ - and $\beta$-subunits of two different $\alpha \beta$ monomers in the $(\alpha \beta)_{3}$ trimer. In spite of being located near that interface the PEB $166 \alpha$ pigment is completely embedded and only interacts with the $\alpha$-subunit protein except for one watermediated $\mathrm{H}$-bonding contact with the neighboring $\beta$-subunit. The protein microenvironment of this pigment is shown in Fig. $3 \mathrm{~d}$ for the $\alpha$-subunit A (the same arrangement is found for $\alpha$-subunits B...L). Residues Cys82 and Asp85 hold the
PEB166 $\alpha$ molecule in place via the $\mathrm{C}_{\mathrm{PEB}}-\mathrm{S}_{\mathrm{Cys}}$ covalent bond between Cys 82 and PEB ring A, and the two H-bonds between the Asp85 side chain and the pigment's NB and NC atoms of its rings $\mathrm{B}$ and $\mathrm{C}$, respectively. The position of the Asp85 side chain is well fixed by the two H-bonds to Arg84 and by one to Tyr127. The orientation of the PEB 166 $\alpha$ is fixed by the PEB C-ring propionic group interacting via two H-bonds with side chains of residues Lys81 and Arg84, and the PEB B-ring propionic group making several $\mathrm{H}$-bonds to water molecules, of which two also link via $\mathrm{H}$-bonds to residues Lys81 and Leu120 (Leu120 not shown in Fig. 3d). The $\mathrm{C}$-ring propionic group is also $\mathrm{H}$-bonded to two water molecules, one of them linking the two propionic groups together (not shown in Fig. 3d), and another cross-linking to PEB D-ring's NA atom. Finally, beside the $\mathrm{C}_{\mathrm{PEB}}-\mathrm{S}_{\mathrm{Cys}}$ covalent bond, there is also one $\mathrm{H}$-bond between the NA atom of ring $\mathrm{A}$ and residue Ala72 (via main chain carbonyl bond, not shown), which holds the pigment ring $\mathrm{A}$ in place and adds to the stabilization of the deviation of the ring $\mathrm{A}$ from planarity from the central conjugated rings $\mathrm{B}$ and $\mathrm{C}$ of the PEB166 $\alpha$. The PEB D-ring interacts with the surrounding protein via an $\mathrm{H}$-bond to a water molecule, which in turn H-bonds the carbonyl group of residue Cys 71 from a neighboring $\beta$-subunit (not shown in Fig. 3d). Full details of the H-bonds to water molecules and of all hydrophobic interactions are shown in Fig. S1D in the Supplementary Material.

The fifth chromophore, PEB $188 \beta$ of the $\beta$-subunit, is also a 'high-deviation' chromophore located on the outer surface of the hexamer but its particular interactions with the protein, in the PE structure from Phormidium sp. A09DM reported here, are influenced by the 146-152 insertion (Kumar et al. 2016) in the neighboring protein loop and are, therefore, different from those seen in PE proteins without this insertion [see for instance B-phycoerythrin from Porphyridium (P.) cruentum, PDB ID: 3v57 (Camara-Artigas et al. 2012)]. The protein microenvironment of this pigment is shown in Fig. 3e, $\mathrm{f}$ for the $\beta$-subunits $\mathrm{N}$ and $\mathrm{M}$, respectively. First of all, the PEB $188 \beta$ molecule is uniquely linked to the protein via two $\mathrm{C}_{\mathrm{PEB}}-\mathrm{S}_{\mathrm{Cys}}$ covalent bonds on the two ends of the pigment, to Cys48 at the A-ring end, and to Cys59 at the D-ring end. Additionally, two H-bonds are formed between the side chain of Asp52 and the pigment's NB and NC atoms of its rings $\mathrm{B}$ and $\mathrm{C}$, respectively, while the position of this Asp52 side chain is well fixed by the H-bond to residue Gln 135 and the water-mediated H-bond to Arg148 main chain carbonyl group (this last interaction is not shown in Fig. 3e, f, full details of the PEB188 $\beta$ contacts with water molecules and of all hydrophobic interactions are shown in Fig. S1E, F in the Supplementary Material). All these interactions fix rigidly the position of the PEB188 $\beta$ molecule in the $\beta$-subunit and they are common for all the $12 \beta$-subunits in the PE structure from Phormidium sp. A09DM. These interactions, except 
for the contact to $\operatorname{Arg} 148$, are also observed in PE structures without the 146-152 insertion such as PE from $P$. cruentum (Camara-Artigas et al. 2012). The PEB B-ring propionic group forms two H-bonds to residue Ser145 and one to a water molecule, which is also H-bonded to the A-ring NA atom of the PEB $188 \beta$ molecule. First two of these interactions help to fix the orientation of the PEB188 $\beta$ pigment, while the third one helps to define the deviation of the ring A from planarity relative to the central conjugated rings B and $\mathrm{C}$ of the PEB188 $\beta$. All these interactions are common for all twelve $\beta$-subunits, and are similar to those found in PE from P. cruentum (Camara-Artigas et al. 2012) except that Ser145 is effectively replaced there by Thr147.

In contrast to the above discussion, the interactions of the PEB C-ring propionic group with the protein in the $\mathrm{pH} 7.5$ structure of PE from Phormidium sp. A09DM reported here vary depending on which $\beta$-subunit is being discussed. The situation found in ten $\beta$-subunits, from $\mathrm{N}$ to $\mathrm{W}$, is shown in Fig. 3e, where the PEB C-ring propionic group is H-bonded to the side chain of $\operatorname{Arg} 127$, the position of which is fixed by two H-bonds to the side chain of Glu60 (in two cases out of ten, in $\beta$-subunits $\mathrm{P}$ and $\mathrm{S}$, this interaction is mediated by a water molecule). The side chain of Arg148, a residue from the 146-152 insertion, has a strong $\pi$-stacking interaction with the central conjugated portion of the PEB188 $\beta$, in particular with its $\mathrm{C}$-ring. This residue forms also an $\mathrm{H}$-bond to an ND atom of the pyrrole ring D of PEB. A completely different situation was found in two remaining $\beta$-subunits, $M$ and $X$, which is shown for $\beta$-subunit $M$ in Fig. 3f. The PEB C-ring propionic group here turns away from the side chain of Arg127, while the side chain of Arg148 is bent and no longer involved in a $\pi$-stacking interaction with the conjugated PEB ring system. In their different conformations the C-ring propionic acid and the $\operatorname{Arg} 148$ in $\beta$-subunit $\mathrm{M}$ are linked by two $\mathrm{H}$-bonds mediated by a water molecule (not shown if Fig. 3f, see Fig. S1F for details of all PEB interactions). Additionally, both PEB propionic groups and the side chain of Arg148 form several H-bonds mediated by water molecules to residues Thr122 and Thr123 from the $\beta$-subunit $\mathrm{W}$ of the neighboring hexamer in the crystal lattice. In case of $\beta$-subunit $X$, which is located on the second independent hexamer in this crystal structure, the Arg 148 was fitted into the electron density with two alternative conformations of the side chain and these make $\mathrm{H}$-bonds to C-ring propionic acid either directly or via a molecule of water. Again, both PEB propionic groups and the side chain of Arg148 form several H-bonds mediated by water molecules to residues Thr122 and Thr123 but this time from the $\beta$-subunit $\mathrm{N}$ of another neighboring hexamer in the crystal lattice. Finally, in the $\beta$-subunits $\mathrm{N}$ to $\mathrm{W}$, the PEBs ring $\mathrm{D}$ beside being linked to protein by the $\mathrm{C}_{\mathrm{PEB}}-\mathrm{S}_{\mathrm{Cys}}$ covalent bond forms a water-mediated H-bond to residue Glu60 and another H-bond to $\pi$-stacked side chain of Arg148, of which the latter was mentioned already earlier. In the $\beta$-subunits $M$ and $X$, the PEBs ring $D$ beside being bonded to the protein via $\mathrm{C}_{\mathrm{PEB}}-\mathrm{S}_{\mathrm{Cys}}$ covalent bond forms water-mediated $\mathrm{H}$-bonds to the C-ring propionic group and to Glu60. These interactions help to hold the pigment's ring D in place and in its particular orientation.

The earlier structure of PE from Phormidium sp. A09DM at pH 8.5 (PDB ID: 5aqd; Kumar et al. 2016) showed similar structural differences for the pigment PEB $188 \beta$ and its protein interactions between the ten $\beta$-subunits $\mathrm{N}$ to $\mathrm{W}$, and two $\beta$-subunits $\mathrm{M}$ and $\mathrm{X}$. However, in the structure at $\mathrm{pH} 5$ all 12 $\beta$-subunits showed the same organization (like in $\beta$-subunits $\mathrm{N}$ to $\mathrm{W}$ in $\mathrm{pH} 8.5$ structure) around PEB $188 \beta$. Although, the authors of the earlier work (Kumar et al. 2016) concluded that the difference between these two crystal structures was connected with the $\mathrm{pH}$ difference of two crystallization conditions, they could not explain why all $\beta$-subunits in the $\mathrm{pH}$ 8.5 structure did not also show an identical organization of the PEB188 $\beta$ binding site. Examination of the crystal packing of our pH 7.5 $1.14 \AA$ structure shows that the crystal contacts with the neighboring hexamers are different for the PEB $188 \beta$ pigment, and for protein residues in this PEB's vicinity, in the $\beta$-subunits $M$ and $X$ compared to those in $\beta$-subunits $\mathrm{N}$ to $\mathrm{W}$. As described above, the PEB188 $\beta$ pigment and residue $\operatorname{Arg} 148$ in the $\beta$-subunits $\mathrm{M}$ and $\mathrm{X}$ make water-mediated contacts with residues Thr122 and Thr123 of the $\beta$-subunits $\mathrm{W}$ or $\mathrm{N}$ of the neighboring hexamers, respectively. We found that none of the PEB188 $\beta$ pigments in the ten $\beta$-subunits $\mathrm{N}$ to $\mathrm{W}$ form such crystal contacts in this region.

It was also found that $\mathrm{C} \alpha$-carbon of the $\operatorname{Arg} 148$ in the $\beta$-subunits $\mathrm{M}$ and $\mathrm{X}$ is located at a distance of $5.09 \AA$ from the NB atom, the nearest atom of the PEB $188 \beta$ pigment, while this distance for $\beta$-subunits $\mathrm{N}$ to $\mathrm{W}$ was found to be in a range of 4.74-4.89 $\AA$. The difference in these distances, between $\mathrm{M} / \mathrm{X}$ and $\mathrm{N}$-to-W subunits, is in the range of 0.2-0.35 $\AA$, so is about ten times larger than the estimated coordinate error $0.03 \AA$ for the $1.14 \AA$ structure. It is therefore highly significant and explains why $\pi$-stacking between Arg 148 and PEB $188 \beta$ is not formed in $\beta$-subunits $\mathrm{M}$ and X. Remodelling of the side chain conformation for the $\operatorname{Arg} 148$ residue from $\beta$-subunit $M$ has shown that when this side chain is made approximately parallel to the PEB's C-ring to mimic the $\pi$-stacking to PEB $188 \beta$, the shortest distance between the two planes is about 3.9-4.0 $\AA$ while an optimal $\pi$-stacking distance is expected to be $\sim 3.6 \AA$. Distances in the range of 3.57-3.66 $\AA$ were found for all Arg 148 $\pi$-stacking cases for the $\beta$-subunits $\mathrm{N}$ to $\mathrm{W}$. These modelling trials reinforce significance of the differences between the $\mathrm{M} / \mathrm{X}$ and N-to-W subunits and the effect they have on the $\pi$-stacking, which explains why efficient $\pi$-stacking is not formed in $\beta$-subunits $\mathrm{M}$ and $\mathrm{X}$ and the $\operatorname{Arg} 148$ side chain assumes different conformation. Examination of the $\mathrm{pH} 5$ 
Table 2 Conservation of PE residues interacting with the PEB pigment molecules. Total of 37 orthologous sequences for PE- $\alpha$ and 34 for PE- $\beta$ from the NCBI database were taken into consideration to analyse conservation (see Supplementary Material Fig. S2 for more details); (A) details of covalent bonds $\mathrm{C}_{\mathrm{PEB}}-\mathrm{S}_{\mathrm{Cys}}$ for each of PEB chromophores and conservation of the involved Cys amino acids; ' $\mathrm{X}$ ' stands for non-conserved position; (B) list of H-bonds involved in chromophore-protein interactions and conservation of the involved amino acids; ' $\mathrm{x}$ ' stands for non-conserved position

\begin{tabular}{|c|c|c|c|c|}
\hline \multicolumn{2}{|l|}{$\mathrm{PEB}$, atom } & \multicolumn{2}{|c|}{ Cys residue, atom } & \multirow[t]{2}{*}{ Conserved motif } \\
\hline \multicolumn{4}{|l|}{ (A) } & \\
\hline PEB166 $\alpha$ & Ring A, CAA & Cys 82 & SG & 81-KCxRD-85 \\
\hline PEB $167 \alpha$ & Ring A, CAA & Cys139 & SG & 137-RxC-139 \\
\hline PEB186 $\beta$ & Ring A, CAA & Cys80 & SG & 78-AACL-81 \\
\hline PEB187 $\beta$ & Ring A, CAA & Cys165 & SG & 164-(D/R)C(A/S)-166 \\
\hline PEB188 $\beta$ & Ring A, CAA & Cys48 & SG & 45-NASC-48 \\
\hline PEB $188 \beta$ & Ring D, CAD & Cys59 & SG & 58-ICE-60 \\
\hline \multicolumn{2}{|l|}{ Chromophore } & \multicolumn{2}{|l|}{ Protein } & \multirow[t]{2}{*}{ Conserved motif (if conserved) } \\
\hline PEB & Atom & Residue & Atom & \\
\hline \multicolumn{5}{|l|}{ (B) } \\
\hline \multirow[t]{6}{*}{ PEB166 $\alpha$} & Ring A, NA & Ala72 & $\mathrm{O}$ & 70-GEA-72 \\
\hline & Ring $\mathrm{C}, \mathrm{O} 1 \mathrm{C}$ & Lys81 & $\mathrm{NZ}$ & 81-KCxRD-85 \\
\hline & Ring $\mathrm{C}, \mathrm{O} 2 \mathrm{C}$ & $\operatorname{Arg} 84$ & NH1 & 81-KCxRD-85 \\
\hline & Ring $\mathrm{C}, \mathrm{O} 2 \mathrm{C}$ & & NH2 & \\
\hline & Ring B, NB & Asp85 & OD2 & 81-KCxRD-85 \\
\hline & Ring $\mathrm{C}, \mathrm{NC}$ & & OD2 & \\
\hline \multirow[t]{4}{*}{ PEB $167 \alpha$} & Ring B, O1B & $\operatorname{Arg} 137$ & $\mathrm{NH} 2$ & 135-RxR-137 \\
\hline & Ring B, O2B & & NH1 & \\
\hline & Ring C, O1C & Arg142 & $\mathrm{NH} 2$ & 141-PRD-143 \\
\hline & Ring $\mathrm{C}, \mathrm{O} 2 \mathrm{C}$ & & NH1 & \\
\hline \multirow[t]{8}{*}{ PEB186 $\beta$} & Ring A, NA & MeN70 & OD1 & 68-GGNCYP-73 \\
\hline & Ring B, O2B & $\operatorname{Arg} 75$ & NH1 & 75-RRMA-78 \\
\hline & Ring B, O1B & $\operatorname{Arg} 76$ & $\mathrm{NH} 2$ & 75-RRMA-78 \\
\hline & Ring B, O1B & & $\mathrm{NE}$ & \\
\hline & Ring $\mathrm{C}, \mathrm{O} 2 \mathrm{C}$ & Arg82 & NH1 & 80-CLRD-83 \\
\hline & Ring C, O2C & & $\mathrm{NH} 2$ & \\
\hline & Ring B, NB & Asp83 & OD2 & 80-CLRD-83 \\
\hline & Ring $\mathrm{C}, \mathrm{NC}$ & & OD2 & \\
\hline \multirow[t]{8}{*}{ PEB $187 \beta$} & Ring D, OD & $\mathrm{Gln} 28$ & NE2 & 27-(V/I)QG-29 \\
\hline & Ring D, ND & Asn33 & OD1 & 32-(G/A)N(R/K)R-35 \\
\hline & Ring B, O1B & Arg34 & $\mathrm{NE}$ & 32-(G/A)N(R/K)R-35 \\
\hline & Ring B, O2B & & $\mathrm{NH} 2$ & \\
\hline & Ring B, NB & Asp37 & OD2 & 33-N(R/K)RLDA-38 \\
\hline & Ring $\mathrm{C}, \mathrm{NC}$ & & OD2 & \\
\hline & Ring A, NA & Pro159 & $\mathrm{O}$ & $\begin{array}{l}\text { Main chain carbonyl- } O \text { conserved } \\
\text { irrespactable to primary sequence }\end{array}$ \\
\hline & Ring A, OA & Val161 & $\mathrm{O}$ & $\begin{array}{l}\text { Main chain carbonyl-O conserved } \\
\text { irrespactable to primary sequence }\end{array}$ \\
\hline \multirow[t]{6}{*}{ PEB $188 \beta$} & Ring B, NB & Asp52 & OD2 & 50-VSDA-53 \\
\hline & Ring $\mathrm{C}, \mathrm{NC}$ & & OD2 & \\
\hline & Ring C, O1C & Agr127 & NH1 & 127-RAV-129 \\
\hline & Ring B, O1B & Ser145 & $\mathrm{N}$ & 144-x(S/T)x-146 \\
\hline & Ring B, O2B & & OG & \\
\hline & Ring C, ND & Arg148 & NH1 & 146-152 loop insertion, not conserved \\
\hline
\end{tabular}




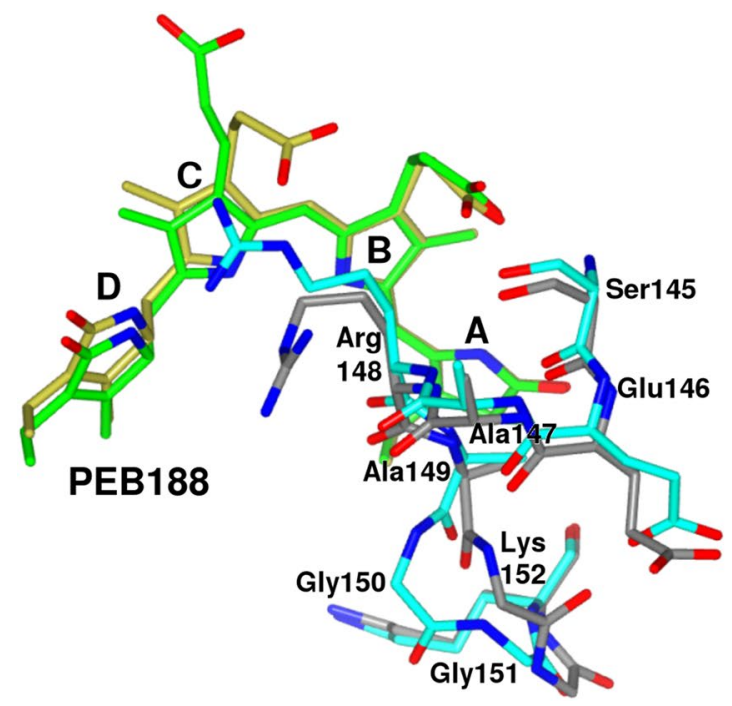

Fig. 4 Stereo view of superimposed models of the inserted loop Glu146-Lys152 partially overlapping chromophore PEB188 in $\beta$-subunit $N$ (cyan protein chain and green chromophore) and in $\beta$-subunit $\mathrm{M}$ (grey protein chain and golden chromophore). The con-

structure (PDB ID: 5fvb; Kumar et al. 2016) revealed that equivalent hexamer-hexamer contacts in the vicinity of the PEB $188 \beta$ pigment also exist for $\beta$-subunits $\mathrm{M}$ and $\mathrm{X}$ but the gap between the hexamers is a bit wider (by at least two layers of water). This explains why the PEB188 $\beta$ pigment structures in $\beta$-subunits $\mathrm{M}$ and $\mathrm{X}$ are not significantly different from those in $\beta$-subunits $\mathrm{N}$ to $\mathrm{W}$ at $\mathrm{pH} 5$ but are different at pHs 7.5 and 8.5. This type of detailed discussion was not possible for the previous crystal structures of PE from Phormidium sp. A09DM due to their limited resolution.

All five PEB pigments are involved in multiple interactions with the surrounding apo-proteins. These interactions can be divided into three groups. The first group includes the $\mathrm{C}_{\mathrm{PEB}}-\mathrm{S}_{\mathrm{Cys}}$ covalent bond to the A-ring of the PEB molecule (or two such covalent bonds to rings $A$ and $D$ in case of PEB 188 $\beta$ ) and an aspartate residue, which forms two $\mathrm{H}$-bonds to the pigment's $\mathrm{NB}$ and $\mathrm{NC}$ atoms of its rings $\mathrm{B}$ and $\mathrm{C}$, respectively (in case of PEB $167 \alpha$ pigment this interaction is mediated by a water molecule). These interactions anchor the PEB molecules in a specific place within the protein scaffold. The second group of interactions includes a variety of $\mathrm{H}$-bonds to $\mathrm{PEB} \mathrm{B}$ - and $\mathrm{C}$-ring propionic acid groups that fix the orientation of these two rings of PEB so that the conjugated system is well maintained. This orientation of the B- and C-rings is additionally stabilized in some cases by the $\pi$-stacking with key arginine residues. The third group of interactions involves a set of H-bonds that control deviation of the PEB A-ring relative to the axis defined by B- and C-rings. These three groups of interactions are most important for controlling the spectroscopic and energy

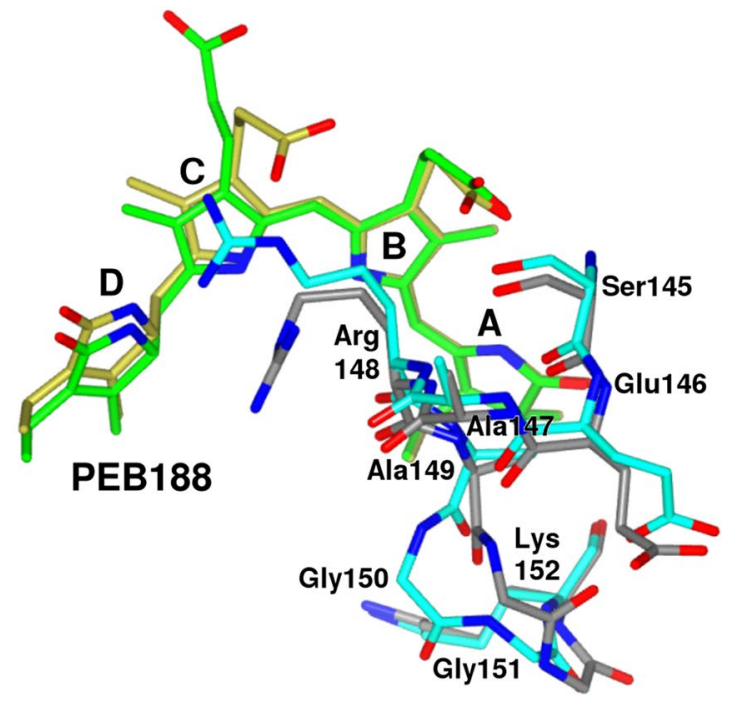

formation of this loop in nine $\beta$-subunits $\mathrm{O}$ to $\mathrm{W}$ is the same as in $\beta$-subunit $\mathrm{N}$, while the conformation in $\beta$-subunit $\mathrm{X}$ is the same as in M. This figure was prepared using CCP4mg (McNicholas et al. 2011)

transfer properties of the pigment molecules. There are also some H-bond interactions that control the orientation of PEB's ring D relative to the axis of the B- and C-rings but these are less important functionally since ring $\mathrm{D}$ is not in conjugation with rings $\mathrm{B}$ and $\mathrm{C}$. Table 2 summarizes all the interactions of PEB chromophores with the protein PE from Phormidium sp. A09DM discussed above and provides information about the conservation of these residues among available PE sequences from diverse cyanobacterial species. Total 37 orthologous sequences to PE- $\alpha$ and 34 to PE- $\beta$ have been mined from the NCBI database and used for this analysis (these sequences are listed in the Supplementary Material Fig. S2). All of the interacting residues, except for the Arg148 from the insertion 146-152 in the $\beta$-subunits, are strongly conserved. The microenvironments of the PEB chromophores in the PE are remarkably highly conserved.

\section{Conformation of the protein loop near the PEB188p pigment}

In PE from Phormidium sp. A09DM there is an insertion of 7 amino acids in the $\beta$-subunits relative to the sequence of most PEs (whose crystal structures are available), which forms an extension at the end of the large loop (that is composed of residues 143-161) in vicinity of the PEB188 $\beta$ pigment. This insert wraps over the top of the PEB188 $\beta$ on its solvent phase side and contributes the important Arg 148 residue whose role was described above. The NCBI database of 34 sequences of $\beta$-subunits of $\mathrm{PE}$ from different species of cyanobacteria that contain this insertion loop (of 
length of 7-9 amino acids) has been analysed. A multiple sequence alignment table for these sequences is shown in Fig. S2 in the Supplementary Material. Although there is a certain degree of sequence conservation in this insertion there are no positions where the type of amino acid is completely conserved. Moreover, an X-ray crystal structure for $\mathrm{PE}$ containing this insertion is only available for the species of cyanobacteria used here.

In the $1.14 \AA$ structure of PE from Phormidium sp. A09DM reported here an interesting curiosity about the conformation of this insertion was found. Namely, the 149-152 fragment of this insertion was found to be in two different main chain conformations in the crystal structure. One conformation is seen in ten $\beta$-subunits, $\mathrm{N}$ to $\mathrm{W}$, and is associated with the Arg $148 \pi$-stacking with the PEB188 $\beta$ molecule. The alternative second conformation is seen in $\beta$-subunits $\mathrm{M}$ and $\mathrm{X}$, where the $\operatorname{Arg} 148$ does not form the $\pi$-stacking interaction with the PEB188 $\beta$. These two main chain conformations of the loop together with the associated PEB $188 \beta$ molecules are shown overlaid in Fig. 4. An obvious conclusion would be to suggest that these two conformations are correlated with the type of interactions $\operatorname{Arg} 148$ has with the chromophore PEB $188 \beta$ and are a consequence of these interactions. However, another of the two PE structures we are reporting here, the one refined based on the $1.38 \AA$ data obtained for the crystal grown in the mix of carboxylic acids (Morpheus screen G8 condition) presents another case. In that structure, the conformation of the 146-152 fragment of the loop in $\beta$-subunits $\mathrm{M}$ and $\mathrm{X}$ is the same as in the $1.14 \AA$ structure, but the situation in $\beta$-subunits $\mathrm{N}$ to $\mathrm{W}$ is different. The electron density maps for this structure suggested presence of both conformations, therefore the fragment $146-152$ of the loop in these ten $\beta$-subunits was modelled using a mixture of both conformations observed in $1.14 \AA$ structure in the ratio of approximately $60: 40 \%$, i.e. with a slightly higher contribution of the conformation present in $\beta$-subunits $\mathrm{M}$ and $\mathrm{X}$. Confusingly, at the same time the $\operatorname{Arg} 148 \pi$-stacking interactions with the PEB188 $\beta$ pigment are identical to those seen in $1.14 \AA$ structure, i.e. different in $\beta$-subunits $\mathrm{M} / \mathrm{X}$ compared to the situation in subunits $\mathrm{N}$ to $\mathrm{W}$. The reason for this complication is not clear but probably reflects the differences in the crystallization conditions used to produce these two crystal forms. Examination of the

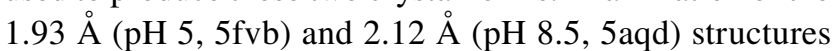
(Kumar et al. 2016) revealed still another situation, namely all the $\beta$-subunits in both structures were modelled with one loop conformation (the one seen in our $\beta$-subunits $\mathrm{M}$ and $\mathrm{X}$ ). However, there were also residual electron densities in the vicinity of this loop that suggested some partial presence of the alternative conformation as well, but modelling of these alternative conformations was not attempted at these lower resolutions. These findings reiterate the unquestionable value of being able to examine crystal structures at the atomic resolution.

\section{Additional structural features}

In our $1.14 \AA$ structure of PE (crystals grown in Morpheus C 8 conditions) $\alpha$-subunits of two trimers are bridged by three well-ordered nitrate anions $\left(\mathrm{NO}_{3}{ }^{-}\right)$each forming contacts with two threonine residues (Thr124) from two $\alpha$-subunits across each boundary between $\left[(\alpha \beta)_{3}\right]$ trimers. The details of this interaction are illustrated in Fig. 5. Apart from the $\mathrm{H}$-bonds to the threonine residues the nitrate anion is $\mathrm{H}$-bonded to $\mathrm{Arg} 118$ residues and through well-ordered water molecules to Tyr65 residues at the trimer: trimer interface. It is worth noting that in this case nitrate ions were present in the crystallization conditions containing the NPS

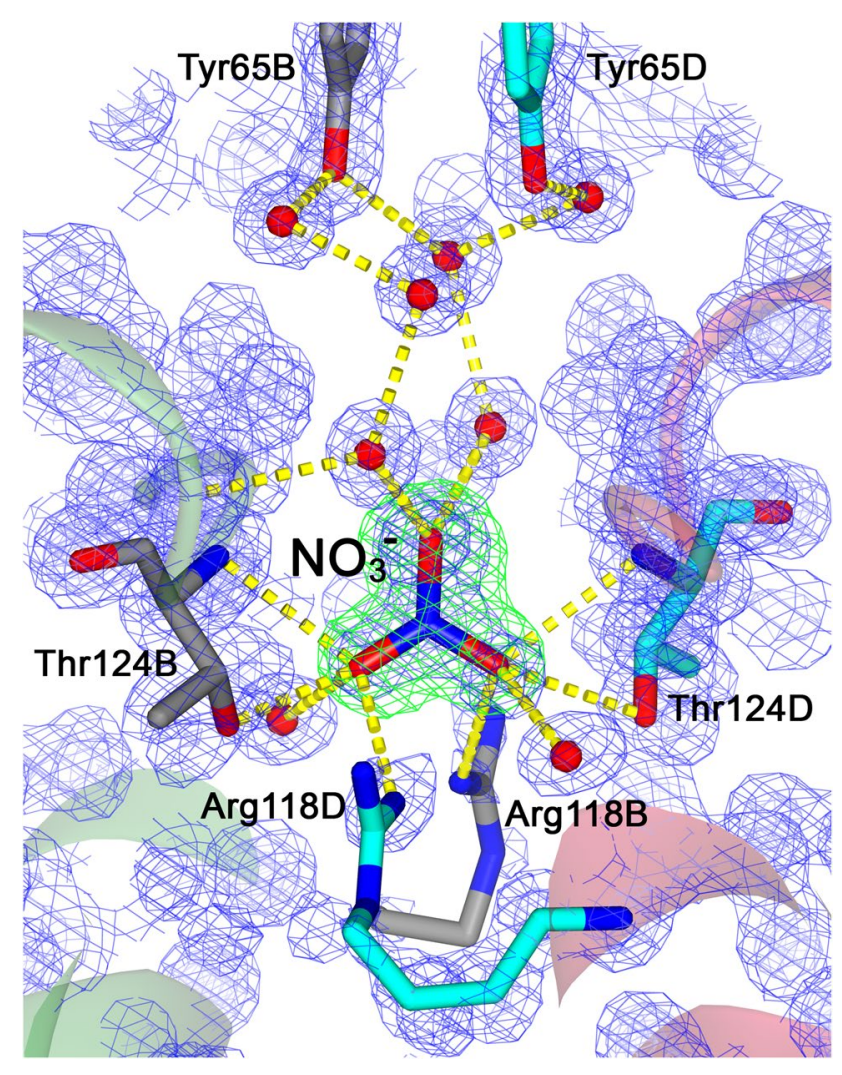

Fig. 5 A representative example of one of the six nitrate $\left(\mathrm{NO}_{3}{ }^{-}\right)$anions that bridge four PE trimers by $\mathrm{H}$-bonding network to form two hexamers $\left\{\left[(\alpha \beta)_{3}\right]_{2}\right\}$. The $\mathrm{NO}_{3}{ }^{-}$anion together with several water molecules make an 'H-bridge' by involvement of Thr124, Arg118 and Tyr65 residues from $\alpha$-subunits B (cyan) and D (grey) of two trimers. Hydrogen bonds are presented as yellow dashed lines. Water molecules are shown as red spheres. Electron density map $2 F o-F C$ and the omit difference Fourier map (for the $\mathrm{NO}_{3}{ }^{-}$anion) are shown as blue and green meshes at contour levels 1.5 sigma and 4.0 sigma, respectively. This figure was prepared using $C C P 4 \mathrm{mg}$ (McNicholas et al. 2011) 


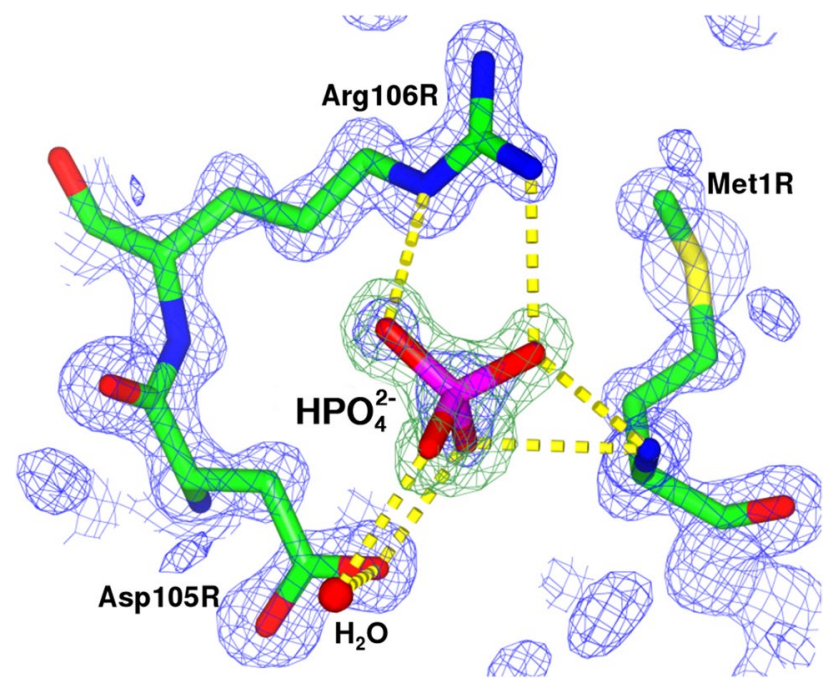

Fig. 6 A representative of one of the twelve hydrogen phosphate $\left(\mathrm{HPO}_{4}{ }^{2-}\right)$ ions interacting with $\beta$-subunits at the $\mathrm{N}$-termini by H-bonding to Met1, Asp105 and Arg106 residues. Hydrogen bonds are presented as yellow dashed lines. A water molecule is shown as the red sphere. Electron density map $2 F O-F C$ and the omit difference Fourier map (for the $\mathrm{HPO}_{4}{ }^{2-}$ ion) are shown as blue and green meshes at contour levels 1.5 sigma and 3.0 sigma, respectively. This figure was prepared using CCP4MG (McNicholas et al. 2011)

mix of additives (NPS). Interestingly, in our $1.38 \AA$ structure, where the crystals were grown in the absence of nitrates (in Morpheus G8 conditions, mix of additives: carboxylic acids) the equivalent site to that shown in Fig. 5 is occupied by ordered water molecules alone. This suggests that the binding of nitrate ions in this site is not essential for the stabilization of the hexamer. In the previous study by Kumar et al. (2016), it was shown that this site in the crystal grown at $\mathrm{pH} 8.5$ (PDB ID: 5aqd) could also be occupied by a sulphate anion (where sulphate ions were present in their crystallization conditions).

Crystallization conditions used here that produced the $1.14 \AA$ PE structure also contained phosphate ions. As shown in Fig. 6 phosphate anions, which were modelled as $\mathrm{HPO}_{4}{ }^{2-}$ ions for the crystallization $\mathrm{pH}$ of 7.5 , were found $\mathrm{H}$-bonded to residues Met1, Asp105 and Arg106 at the $\mathrm{N}$-terminal region of each $\beta$-subunit. Another more tentative binding site for phosphate was also identified in the $\alpha$-subunit forming H-bonds with residues Gly112, Arg114 and Glu115. Both these sites are close to the central cavity inside each trimer. These sites in the $1.38 \AA$ structure were occupied by water molecules only.

\section{Fitting the absorption spectrum of PE: implications for energy transfer}

The CD spectrum of PE was recorded in 400-600 nm region. This spectrum just shows a featureless broad positive signal
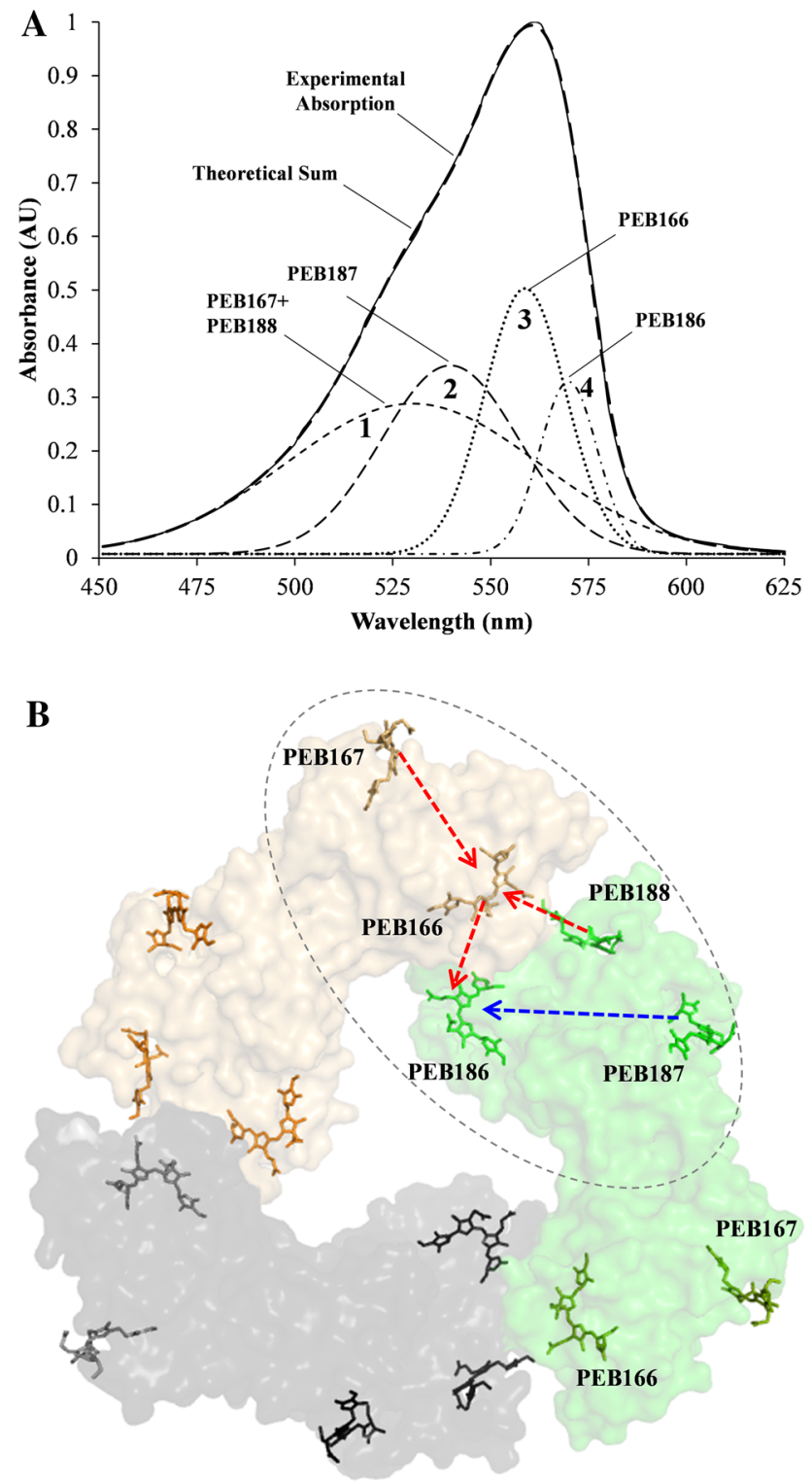

Fig. 7 Deconvolution of the PE absorption spectrum and tentative energy transfer pathways a deconvolution of the PE absorption spectrum into four Gaussian decomposition components designated as dashed-line peaks 1 to 4 associated with the named pigment molecules. Intact line represents the experimental steady-state absorption profile of PE. The quality of the deconvolution fit is shown by the bold dashed line that represents the addition of the four deconvoluted Gaussian components, $\mathbf{b}$ the spatial arrangement of chromophores in the PE trimer and the two proposed energy transfer pathways (represented by the red and blue dashed lines)

throughout this region (see Fig. S3 in the Supplementary Material). More useful information was obtained by deconvolution of the PE absorption spectrum. The best fit for this deconvolution was obtained with four separate Gaussian peaks (Fig. 7a). These peaks have absorption maxima $\left(\lambda_{\max }\right)$ at $530,540,559,570 \mathrm{~nm}$, respectively. Based on the A-Bring planarity data (Table S2) and as described in Doust 
et al. (2004) and Choubeh et al. (2017), these peaks were tentatively assigned to individual chromophores, i.e. Peak $1(530 \mathrm{~nm})$ was assigned to high-energy PEB167 + PEB188 (the contributions of these two pigments could not be further resolved), Peak 2 (540 nm) to PEB187, Peak 3 (559 nm) to PEB166 and Peak $4(570 \mathrm{~nm})$ to low-energy absorbing PEB186 (Fig. 7a). Thus, PEB167 and PEB188 are positioned at blue end of the absorption band, PEB 187 occupies the green region and PEB166 and PEB186 are at red end. The spatial arrangement of chromophores within PE trimer (Fig. 7b) suggests that the $\alpha$ - and $\beta$-chromophores within an $\alpha \beta$-monomer are too far apart for energy transfer, but upon formation of the trimer, the $\alpha$-subunit chromophores of one $\alpha \beta$-monomer come into closer contact with the $\beta$-subunit chromophores of the neighboring $\alpha \beta$-monomer as indicated by the dashed oval in Fig. 7b. In this arrangement, the highenergy absorbing chromophores PEB167, PEB187 and PEB188 (Peak 1 and 2 in Fig. 7a) are located on the periphery, whereas low-energy absorbing chromophores PEB166 and PEB 186 (Peak 3 and 4 in Fig. 7a) are located in middle layer and core, respectively. Using this information it is possible to suggest two pathways for energy transfer from the outwardly positioned high-energy chromophores to the inner low-energy chromophores; first PEB167 + PEB188 $\rightarrow$ PEB166 $\rightarrow$ PEB186 (dashed red arrows in Fig. 7b) and second PEB187 $\rightarrow$ PEB186 (dashed blue arrow in Fig. 7b).

Acknowledgements RRS thanks the British Council and Department of Science and Technology (DST, New Delhi) for a Newton-Bhabha grant to visit Glasgow. RJC and AWR were supported by the Photosynthetic Antenna Research Center (PARC), an Energy Frontier Research Center funded by the Department of Energy, Office of Science, Office of Basic Energy Sciences, under award number DE-SC0001035. We thank Diamond Light Source for access to beamlines I03 (MX1165148), I04 (MX11651-41) and I04-1 (MX11651-45) that contributed to the results presented here.

Open Access This article is distributed under the terms of the Creative Commons Attribution 4.0 International License (http://creativecommons.org/licenses/by/4.0/), which permits unrestricted use, distribution, and reproduction in any medium, provided you give appropriate credit to the original author(s) and the source, provide a link to the Creative Commons license, and indicate if changes were made.

\section{References}

Aghtar M, Kleinekathofer U, Curutchet C, Mennucci B (2017) Impact of electronic fluctuations and their description on the exciton dynamics in the light-harvesting complex PE545. J Phys Chem B 121:1330-1339. doi:10.1021/acs.jpcb.6b10772

Camara-Artigas A, Bacarizo J, Andujar-Sanchez M, Ortiz-Salmeron E, Mesa-Valle C, Cuadri C, Martin-Garcia JM, MartinezRodriguez S, Mazzuca-Sobczuk T, Ibañez MJ, Allen JP (2012) $\mathrm{pH}$-dependent structural conformations of B-phycoerythrin from Porphyridium cruentum. FEBS J 279:3680-3691. doi:10.1111/j.1742-4658.2012.08730.x
Choubeh RR, Sonani RR, Madamwar D, Struik PC, Bader AN, Robert B, van Amerongen H (2017) Picosecond excitation energy transfer of allophycocyanin studied in solution and in crystals. Photosyn Res. doi:10.1007/s11120-017-0417-4

Cruickshank DWJ (1999) Remarks about protein structure precision. Acta Cryst D 55:583-601. doi:10.1107/S0907444998012645

Curutchet C, Mennucci B (2017) Quantum chemical studies of light harvesting. Chem Rev 117:294-343. doi:10.1021/acs. chemrev.5b00700

Curutchet C, Kongsted J, Muñoz-Losa A, Hossein-Nejad H, Scholes GD, Mennucci B (2011) Photosynthetic light-harvesting is tuned by the heterogeneous polarizable environment of the protein. J Am Chem Soc 133:3078-3084. doi:10.1021/ja110053y

Curutchet C, Novoderezhkin VI, Kongsted J, Munoz Losa A, van Grondelle R, Scholes GD, Mennucci B (2013) Energy flow in the cryptophyte PE545 antenna is directed by billin pigment conformation. J Phys Chem B 117:4263-4273. doi:10.1021/ jp305033d

Doust AB, Marai CN, Harrop SJ, Wilk KE, Curmi PM, Scholes GD (2004) Developing a structure-function model for the cryptophyte phycoerythrin 545 using ultrahigh resolution crystallography and ultrafast laser spectroscopy. J Mol Biol 344:135-143. doi:10.1016/j.jmb.2004.09.044

Emsley P, Lohkamp B, Scott W, Cowtan K (2010) Features and development of coot. Acta Cryst D 66:486-501. doi:10.1107/ S0907444910007493

Evans PR (2006) An introduction to data reduction: space-group determination, scaling and intensity statistics. Acta Cryst D 67:282-292. doi:10.1107/S090744491003982X

Evans PR, Murshudov GN (2013) How good are my data and what is the resolution? Acta Cryst D 69:1204-1214. doi:10.1107/ S0907444913000061

Gaigalas A, Gallagher T, Cole KD, Singh T, Wang L, Zhang YZ (2006) A multistate model for the fluorescence response of R-phycoerythrin. Photochem Photobiol 82:635-644. doi:10.1562/2005-05-26-RA-544

Kabsch W (2010) XDS. Acta Cryst D 66:125-132. doi:10.1107/ S0907444909047337

Karplus PA, Diederichs K (2012) Linking crystallographic model and data quality. Science 336:1030-1033. doi:10.1126/ science. 1218231

Kumar V, Sonani RR, Sharma M, Gupta GD, Madamwar D (2016) Photosyn Res 129:17-28. doi:10.1007/s11120-016-0259-5

Kupka M, Scheer H (2008) Unfolding of C-phycocyanin followed by loss of non-covalent chromophore-protein interactions: 1 . Equilibrium experiments. Biochim Biophys Acta 1777:94-103. doi:10.1016/j.bbabio.2007.10.009

Laskowski RA, Swindells MB (2011) LigPlot+: multiple ligandprotein interaction diagrams for drug discovery. J Chem Inf Model 51:2778-2786. doi:10.1021/ci200227u

Lovell SC, Davis IW, Arendall WB, De Bakker PIW, Word JM, Prisant MG, Richardson JS, Richardson DC (2003) Structure validation by $\mathrm{C} \alpha$ geometry: $\phi, \psi$ and $\mathrm{C} \beta$ deviation. Proteins 50:437-450. doi:10.1002/prot.10286

McNicholas S, Potterton E, Wilson KS, Noble MEM (2011) Presenting your structures: the CCP4mg molecular-graphics software. Acta Cryst D 67:386-394. doi:10.1107/S0907444911007281

Murshudov GN, Skubak P, Lebedev AA, Pannu NS, Steiner RA, Nicholls RA, Winn MD, Long F, Vagin AA (2011) REFMAC5 for the refinement of macromolecular crystal structures. Acta Cryst D 67:355-367. doi:10.1107/S0907444911001314

Rupp B (2010) Biomolecular crystallography. Principles, practice and application to structural biology. Garland Science, New York, pp 451-453

Sonani RR, Sharma M, Gupta GD, Kumar V, Madamwar D (2015) Phormydium phycoerythrin forms hexamers in crystals: a 
crystallographic study. Acta Cryst F 71:998-1004. doi:10.1107/ S2053230X15010134

Vonrhein C, Flensburg C, Keller P, Sharff A, Smart O, Paciorek W, Womack T, Bricogne G (2011) Data processing and analysis with the autoPROC toolbox. Acta Cryst D 67:293-302. doi:10.1107/S0907444911007773

Winn MD, Ballard CC, Cowtan KD, Dodson EJ, Emsley P, Evans PR, Keegan RM, Krissinel EB, Leslie AGW, McCoy A, McNicholas SJ, Murshudov GN, Pannu NS, Potterton EA, Powell HR, Read RJ, Vagin A, Wilson KS (2011) Overview of the CCP4 suite and current developments. Acta Cryst D 67:235-242. doi:10.1107/ S0907444910045749

Winter G (2010) xia2: an expert system for macromolecular crystallography data reduction. J Appl Cryst 43:186-190. doi:10.1107/ S0021889809045701

Zhao K-H, Porra RJ, Scheer H (2012) Phycobiliproteins. In: Kadish KM, Smith KM, Guilard R (eds) Biophysical and physicochemical studies of tetrapyrroles. Handbook of porphyrin science, vol. 22. World Scientific Publishing Company, Singapore, pp 1-66 